\title{
Molecular Evidence of Helicobacter Pylori Infection in Prostate Tumors
}

\author{
Mohammed S. Al-Marhoon ${ }^{\mathrm{a}} \quad$ Allal Ouhtit $^{\mathrm{b}} \quad$ Aisha O. Al-Abri ${ }^{\mathrm{b}} \quad$ Krishna P. Venkiteswaran $^{\mathrm{a}}$

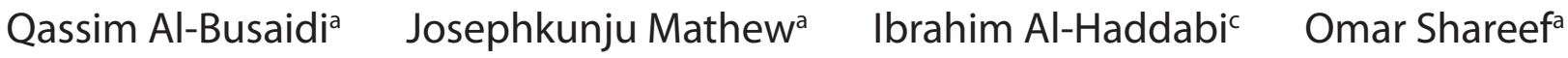 \\ Shahid Aquila Khalid Rahman ${ }^{a} \quad$ Intisar Al-Hashmi ${ }^{a} \quad$ Ishita Gupta ${ }^{b} \quad$ Shyam S. Ganguly ${ }^{d}$

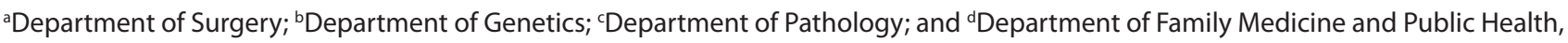 \\ College of Medicine and Health Sciences, Sultan Qaboos University, Al-Khoudh, Oman
}

\author{
Key Words \\ Helicobacter pylori infection • Prostate cancer • \\ Benign prostate hyperplasia $\cdot$ PCR
}

\begin{abstract}
Objectives: To determine whether Helicobacter pylori (H. pylori) is detectable in both benign prostatic hyperplasia (BPH) and prostate cancer (PCa). Epidemiological studies have shown significant associations between infective chronic prostatitis and prostatic carcinoma. Many bacteria have been found in the prostate of patients with chronic prostatitis, $\mathrm{BPH}$, and PCa. Methods: One hundred consecutive patients with prostate diseases were enrolled in the study. Detection of $H$. pylori DNA in prostate tissue from patients with $\mathrm{BPH}$ and PCa was performed using both immunohistochemistry and PCR, and the results were confirmed by DNA sequencing. Odds ratios and the Fisher Exact test were used for the analysis of the associations between the variables. Results: Among the patients, 78\% had BPH and 19\% had PCa. While immunohistochemistry showed no positive sample for $H$. pylori, PCR combined with sequencing detected $H$. pylori DNA in prostate tissue samples from 5 patients. However, statistical analysis of the data showed that BPH and PCa are not significantly associated with the presence of $H$. pylori DNA in prostate tissue (odds ratio $=0.94,95 \%$ confidence interval $=0.09-23.34$, one-tailed Chi-square value $=0.660, \mathrm{p}>0.05$ ) . The limitation of this study was the small number of PCa patients. Conclusions: This study provides, for the first time, molecular evidence of the presence of H. pylori DNA in pros-
\end{abstract}

\section{KARGER}

Fax +4161306 1234

E-Mail karger@karger.ch

www.karger.com
(C) 2014 S. Karger AG, Basel

1015-9770/14/0083-0138\$38.00/0

Accessible online at:

www.karger.com/cur tatic tissue of patients with BPH and PCa. It paves the way for further comprehensive studies to examine the association of H. pylori infection with BPH and PCa.

Copyright @ 2014 S. Karger AG, Basel

\section{Introduction}

Helicobacter pylori (H. pylori) infection is now a rising concern among clinicians and researchers and has been found to cause gastrointestinal [1] and extra-intestinal disorders [2]. According to the World Health Organization $H$. pylori has been classified as a group one (definitive) carcinogen [3]. Various models of gastric carcinogenesis have been developed to describe pathways by which $H$. pylori leads to gastric cancer. One of the models, Correa's multi-step model [4] showed that $H$. pylori infection is a triggering factor in the process of increasingly severe gastric lesions progressing from chronic active gastritis to atrophy, intestinal metaplasia, dysplasia, and gastric cancer. Al-Marhoon et al. [5] proposed a model describing the initial changes induced by $H$. pylori infection that plays a role in protecting the organism and enhancing its colonization in the stomach which can lead to gastric cancer.

There is accumulating evidence relating $H$. pylori infection to urological diseases. The most obvious is the implication of $H$. pylori in inducing chronic cystitis leading to bladder lymphoma [6]. In addition, some 
epidemiological studies have shown significant associations between infective chronic prostatitis and prostatic carcinoma. Al-Marhoon [7] proposed a hypothetical model relating $H$. pylori infection to prostate and bladder diseases. The rationale of this study is based on the following observations: 1) $\mathrm{H}$. pylori has been detected in other organs and is associated with other cancers. 2) Evidence has shown certain infectious agents affect specific areas of the body via systemic sequelae. 3) In a mouse model of chronic bacterial prostatitis induced by Escherichia coli, chronic inflammation caused severe dysplasia and atypical hyperplasia in the prostate [8]. 4) Epidemiological studies showed significant associations between infection and prostatic carcinoma. Furthermore, $78 \%$ of prostatectomy specimens from males suffering from prostate cancer $(\mathrm{PCa})$ or benign prostatic hyperplasia (BPH) were detected to be positive for bacterial DNA [9]. 5) Upon treatment with H. pylori eradication therapy, MALT lymphoma of the urinary bladder disappeared [10]. 6) A study conducted where $H$. pylori was transurethrally inoculated into the mouse urinary tract led to the onset of infection and induced inflammation in the urinary bladder and pelvis [11]. These observations led us to make the aim of our study to provide evidence for the presence of $H$. pylori in both BPH and PCa.

\section{Materials and Methods}

\section{Patients and Study Design}

The study was conducted at Sultan Qaboos University in collaboration between the Department of Urology and Department of Genetics. The study was approved by the local ethics committee, and written informed consent was obtained from each participant. Following a predefined protocol the study recruited 100 consecutive patients with prostatic diseases. Tissue samples were obtained either by transurethral resection or transrectal biopsies of the prostate in the case of BPH and PCa respectively. Infection of $H$. pylori was determined by the presence of $H$. pylori in tissue samples using PCR, histological examination with Giemsa stain, and immunohistochemistry. In addition, $H$. pylori infectivity was determined by the stool antigen test. Exclusion criteria included those patients who were below the age of 18 and above the age of 90 years, those who used proton pump inhibitors and antibiotics within the previous 4 weeks and had severe concomitant diseases, previous gastric surgery, pregnancy or lactation, alcohol abuse, drug addiction, or chronic use of corticosteroids or non-steroidal anti-inflammatory drugs. Patients were diagnosed with lower urinary tract symptoms as defined by the International Continence Society and included irritative and obstructive symptoms.

\section{DNA Extraction}

Post-surgery, the fresh tissue obtained was immediately frozen in liquid nitrogen and then stored at $-80^{\circ} \mathrm{C}$ prior to testing. DNA was extracted from each tissue sample using the QIAamp tissue DNA isolation mini kit (Qiagen, Valencia, CA) as recommended by the manufacturer. Briefly, up to $25 \mathrm{mg}$ of tissue was cut into small pieces, placed in a $1.5 \mathrm{ml}$ microcentrifuge tube, and processed by following the steps described by the manufacturer (Qiagen, Valencia, CA).

\section{$P C R$ and Sequencing}

DNA was directly extracted from each tissue sample and used as a template for the specific detection of the $H$. pylori $16 \mathrm{~S}$ rRNA gene. Nested PCR reactions were performed for the 16S rRNA (product size 423 and 110, respectively) in an Eppendorf Mastercycler Gradient using the following primers: Hp1 (5' - CTG GAG AGA CTA AGC CCT CC - 3'), Hp2 (5'- ATT ACT GAC GCT GAT TGT GC - 3'), and Hp3 (5'- AGG ATC AAG GTT TAA GGA TT - 3') (Metabion, Germany) as previously reported by Ho et al. [12]. A positive control was used in each run (ATCC Helicobacter Pylori 26695, genomic DNA) in addition to a negative control (no DNA). For the first PCR involving Hp1 and Hp3 primers, the following conditions were used: an initial denaturation of $95^{\circ} \mathrm{C}$ for $5 \mathrm{~min}$, then 25 cycles $\left(95^{\circ} \mathrm{C}: 30 \mathrm{~s}, 55^{\circ} \mathrm{C}: 30 \mathrm{~s}, 72^{\circ} \mathrm{C}: 30 \mathrm{~s}\right.$, and final extension $72^{\circ} \mathrm{C}$ for $10 \mathrm{~min}$ ).

The PCR was carried out in $25 \mu \mathrm{l}$ containing $2.5 \mu \mathrm{l}$ of $10 \times \mathrm{PCR}$ buffer (Promega, Madison, WI), $1.5 \mu \mathrm{l}$ of the $25 \mathrm{mM} \mathrm{MgCl}$, $0.3 \mu \mathrm{M}$ of each primer ( $\mathrm{Hp} 1$ and $\mathrm{Hp} 3)$, and $0.5 \mathrm{U}$ of taq DNA polymerase (Ampli Taq Gold, Applied Biosystem, UK). Approximately $100 \mathrm{ng}$ of the isolated DNA was used as a template. For the second PCR including Hp1 and Hp2 primers, the PCR conditions were similar to the first PCR except that the annealing temperature was $60^{\circ} \mathrm{C}$ and $2 \mu \mathrm{l}$ from the first PCR product was used as a template for the second PCR reaction. The PCR products were analyzed by electrophoresis on a $2 \%(\mathrm{w} / \mathrm{v})$ agarose gel (Promega V3121) at $100 \mathrm{~V}$ for $40 \mathrm{~min}$. Gels were stained with ethidium bromide and photographed.

To identify H.pylori in the samples, the PCR product from the second PCR (Hp1 and Hp2, 110 bp) was sequenced in an Eppendorf Mastercycler Gradient using the ABI BigDye ${ }^{\circledR}$ Terminator v3.1 Cycle Sequencing Kit and run on the ABI Genetic Analyzer $3130 x 1$ as recommended by the manufacturer. The conditions of the sequencing reaction included 25 cycles at $96^{\circ} \mathrm{C}(10 \mathrm{~s}), 60^{\circ} \mathrm{C}$ $(5 \mathrm{~s}), 60^{\circ} \mathrm{C}(4 \mathrm{~min})$, and $4^{\circ} \mathrm{C}$ (holding temperature). Sequencing data analysis was performed using the ChromasPro version 1.41 software, a powerful bioinformatic tool to interpret the sequencing results by comparing the normal sequence of the targeted gene CFTR to the tested sequence.

\section{Immunohistochemistry}

Immunohistochemistry was carried out as previously described [13]. Briefly, $5 \mathrm{~mm}$ paraffin sections were predigested with proteinase K (Dako, S3020, Denmark), and incubated with the specific Polyclonal Rabbit anti-helicobacter primary antibody (Dako, B0471, Denmark) diluted 1:50. After further incubation with the biotinylated anti-rabbit secondary antibody (Envision Dual link system HRB, K4061, Dako, Denmark) they were washed in Tris-buffered saline ( $\mathrm{pH} 7.6$ ), and the standard horseradish peroxidase immunohistochemical method was used. The rabbit anti-H. pylori specific polyclonal antibody raised against heat-stable antigens of $H$. pylori strain $\mathrm{CH}-20429$ is highly specific for $H$. pylori and has a sensitivity of $100 \%$ and specificity of $94 \%$ in distinguishing $H$. pylori from other curved bacteria present in the tissues. Heat-stable antigens of $H$. pylori are responsible for a specific humoral immune response in patients infected by this strain. 
Table 1. Demographic data of the 100 patients included in the study

\begin{tabular}{ll}
\hline Characteristics & No. of patients \\
\hline Presentation & \\
LUTS & 66 \\
Urinary retention & 31 \\
Hematuria & 3 \\
Comorbidities & \\
No comorbidities & 29 \\
DM & 7 \\
HTN & 27 \\
DM \& HTN & 13 \\
Others & 18 \\
Unknown & 7 \\
Pathological diagnosis & \\
BPH & 42 \\
Prostate cancer & 19 \\
Prostatitis & 1 \\
BPH and Prostatitis & 36 \\
PIN high grade & 1 \\
Lymphoma & 1 \\
\hline
\end{tabular}

LUTS $=$ Lower urinary tract symptoms; DM = diabetes; HTN = hypertension.

\section{H. Pylori Stool Antigen Test}

The H. pylori antigen rapid test in human fecal specimens (Bioline, SD H. pylori Ag, Standard Diagnostic Inc., Korea) was used to detect $H$. pylori infection as previously described [14].

\section{Statistical Analysis}

Data were analyzed using SPSS (version 15) (SPSS, Chicago, IL, USA). In order to examine the association between the presence of $H$. pylori infection and the type of prostate disease (BPH or $\mathrm{PCa}$ ), odds ratios (ORs) and their $95 \%$ confidence intervals (CI) were estimated and the Fisher Exact test was used. Values of $\mathrm{p}<0.05$ were considered to be statistically significant.

\section{Results}

One hundred consecutive patients with prostate diseases were enrolled in the study. The mean age (mean \pm $\mathrm{SD})$ was $68.7 \pm 8.3$ years. Clinical data and pathological diagnoses are presented in table 1 . The details of the 5 patients positive for $H$. pylori are presented in table 2 . Among the patients, $78 \%$ were diagnosed with $\mathrm{BPH}$ and $19 \%$ with PCa. We initially used immunohistochemistry to examine all the tissue samples for $H$. pylori, and none of the samples were positive for $H$. pylori (data not shown). In contrast, when we used a more sensitive technique such as PCR, H. pylori DNA was detected in 5

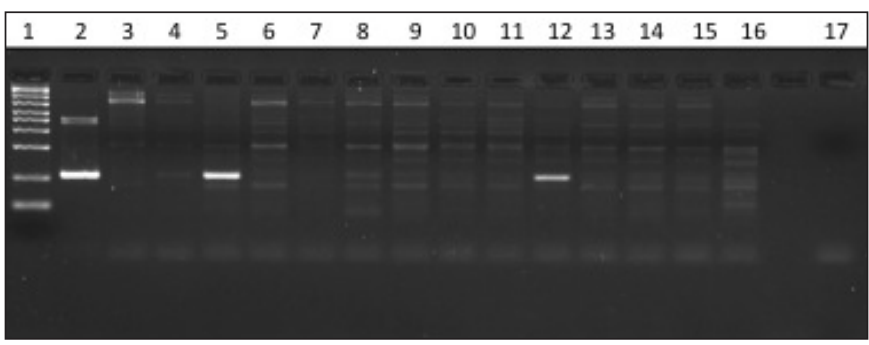

Fig. 1. Nested PCR analysis of prostate tissues. DNA was isolated from prostate tissue samples and analyzed by Nested PCR. Lane 1: 50-2000 bp Ladder; Lane 2: Positive control (H. pylori genomic DNA, 26695), Lane 3: DNA sample from peripheral blood; Lane 5, 12: positive samples, $110 \mathrm{bp}$; Lane 17: Negative control (No DNA); Lane: 4, 6, 7, 8, 9, 10, 11, 13, 14, 15, 16: Negative samples.

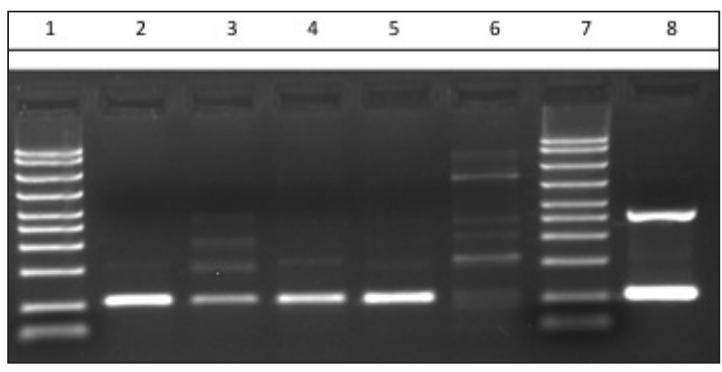

Fig. 2. Confirmation of 4 positive prostate tissue samples by nested PCR. From the 5 positive samples, DNA was analyzed by nested PCR for only 4 samples, because of non-availability of the DNA for further studies. Lane 1, 7: 50-2000 bp Ladder; Lane 2: Positive sample (110 bp); Lane 3: Positive sample (110 bp); Lane 4: Positive sample (110 bp); Lane 5: Positive sample (110 bp); Lane 6: Negative sample; Lane 8: Positive control (H. pylori genomic DNA, 26695).

samples (fig. 1,2). Since 1 of the 5 tissue samples did not generate enough DNA for sequencing, nested PCR and subsequent sequencing analysis were performed for only 4 of the 5 positive samples. The results confirmed the presence of $H$. pylori DNA sequences in these 4 patients (fig. 3). However, statistical analysis of the data showed that $\mathrm{BPH}$ and $\mathrm{PCa}$ are not significantly associated with the presence of $H$. pylori DNA in prostate tissue $(\mathrm{OR}=$ $0.94,95 \% \mathrm{CI}=0.09-23.34$, one tail Chi-square value $=$ $0.660, \mathrm{p}>0.05)$. Interestingly, the $H$. pylori stool antigen test was positive for these 5 patients. 
Table 2. The details of the 5 patients positive for $H$. pylori

\begin{tabular}{lllllll}
\hline Patient & Pathological diagnosis & Age (years) & Presentation & PSA (ng/ml) & PCR & Stool antigen test \\
\hline 1 & BPH \& prostatitis & 66 & LUTS & 0.6 & + & + \\
2 & BPH & 71 & hematuria & 8.9 & + & + \\
3 & Prostate cancer & 71 & LUTS & LUTS & 10.4 & + \\
4 & BPH & 79 & LUTS & 3.8 & + & + \\
5 & BPH \& prostatitis & 79 & & + & + \\
\hline
\end{tabular}

PSA $=$ Prostate specific antigen PCR = polymerase chain reaction.

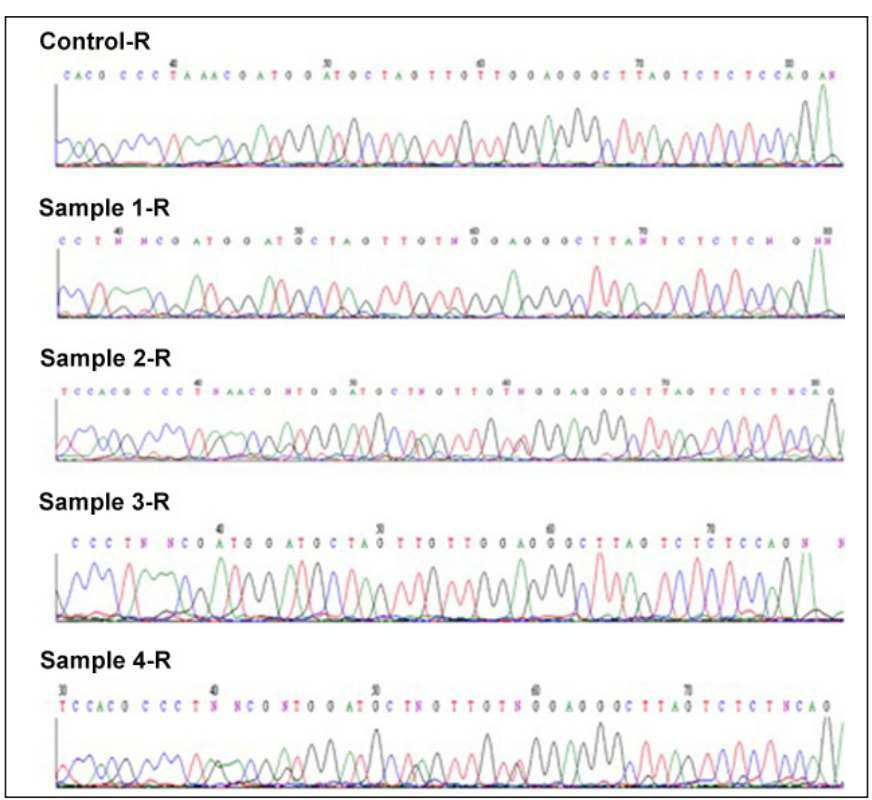

Fig. 3. Sequencing analysis of the DNA from the $4 \mathrm{H}$. pylori positive prostate tissue samples. The DNA from the $4 \mathrm{H}$. pylori positive prostate tissue samples (shown in fig. 2), was subsequently examined by sequencing analysis to confirm the presence of $H$. pylori. Analyzing DNA sequencing results of positive samples (Sample 1-4), and the positive control (using $\mathrm{Hp} 2$ primer).

\section{Discussion}

Accumulating evidence suggests an association of H. pylori infection and urological diseases. Our study is the first to show evidence of the presence of $H$. pylori DNA in the prostatic tissue of patients with BPH and PCa. We employed 2 different approaches: while immunohistochemistry results were negative, PCR allowed us to detect $H$. pylori infection in $5 \%$ of the prostate tissue analyzed from patients with BPH and PCa. One possi- ble explanation for the discordance between PCR and immunohistochemistry might be the fact that samples were embedded in paraffin, however, in situ hybridization which was not done in the present study may have improved $H$. pylori detection in the tissues using immunohistochemical methods.

The link between chronic inflammation and cancer has been recognized for many years [15]. However, the underlying mechanism of the interaction between inflammatory cells and their elaborated factors and tumor cells still remains nascent. Originally, inflammation was assumed to be principally a beneficial host response, representing the body's fight against invading tumor cells. However, in contrast, recent data suggests inflammation to be a cause for the onset of certain cancers and a powerful trigger for tumor growth and invasion [15]. Interestingly, there are numerous data supporting the association of chronic long-standing inflammation and increased risk of tumors of the gastrointestinal tract [16]. In addition, systemic non-steroidal anti-inflammatory drug use has been found to be linked with a significant loss of tumor growth in the bowel, lung, liver, and prostate [17]. A recent study showed that Propionibacterium acnes was detected in $35 \%$ of radical prostatectomy specimens [18] thus indicating that along with genetic factors, environmental factors (e.g. lifestyle, microbial infection, and underlying subclinical prostatitis) also tend to play a role in prostate carcinogenesis.

Various reviews have highlighted the role of infections as a cause of cancer [19]. The major infectious agents trigger cancer by the following mechanisms which demonstrate that inflammation is a crucial aspect of oncogenesis attributable to infection: 1) infect and transform lymphoid cells e.g. Epstein-Barr virus leading to Burkitt's lymphoma [19], 2) transformation e.g. human papillomavirus leading to cervical cancer [20], 3) inflammation and partial integration e.g. hepatitis B vi- 
rus leading to hepatocellular carcinoma [20], 4) chronic inflammation and oncogenic proteins e.g. hepatitis $\mathrm{C}$ virus leading to hepatocellular carcinoma [19], 5) chronic stimulation of lymphocytes by pathogen antigens and/or autoantigens e.g. H. pylori leading to gastric lymphoma [21], 6) chronic inflammation e.g. H. pylori leading to gastric and esophageal adenocarcinoma [22] and Schistosomiasis leading to bladder cancer [20], 7) chronic inflammation possible associations e.g. Propionibacterium acnes leading to $\mathrm{PCa}[18]$ and Mycoplasma species leading to PCa [23], and 8) immunosuppression e.g. HIV leading to Epstein-Barr virus + central nervous system lymphomas [19]. As mentioned above, it is known that certain infectious agents tend to affect specific areas of the body through systemic sequelae. Karatas et al. [24] investigated the possible relationship between $H$. pylori infection and chronic prostatitis/chronic pelvic pain syndrome (CP/CPPS) and found the seropositivity for the antibody against $H$. pylori to be higher in the CP/CPPS group than in the control group ( $\mathrm{p}<0.05)$, thus concluding that $H$. pylori is involved in CP/CPPS. It was further recommended that $H$. pylori must be investigated in prostate biopsy material.

One of the major drawbacks of molecular-based techniques for microbial detection is the persistent threat of artifact and/or false-positive results due to highly sensitive methods for detection as well as the constant threat of potential contamination. A very recent and relevant example of this concern involves the controversy surrounding the discovery of a novel murine retrovirus, termed $\mathrm{XMRV}$, in PCa samples from patients with homozygous germline RNase L mutations [25]. A study conducted by Barykova et al. [26] highlighted the important efforts underway to identify potential infectious agents that could be possibly linked to chronic inflammation as commonly observed in PCa patients, which could be potentially associated with its development. Future work involving establishing a probable causal role for microorganism(s) in prostate carcinogenesis should include efforts to localize the organism(s) of interest in PCa tissues in order to determine if the presence of the organism correlates to its histo-pathological features including patterns of inflammation, or prostatic lesions (atrophy, prostatic intraepithelial neoplasia, cancer). The identification of $H$. pylori in the stomach of cancer patients and the association of $H$. pylori with gastric inflammation and gastric atrophy helped to form the body of evidence that eventually proved that $H$. pylori plays an etiologic role in gastric carcinogenesis. In the present study we have for the first time demonstrated by molecular evidence the presence of
H. pylori DNA in patients with $\mathrm{BPH}$ and prostatitis and 1 patient with $\mathrm{PCa}$. The limitations of this study include the small number of $\mathrm{PCa}$ patients to provide statistical difference between $\mathrm{BPH}$ and $\mathrm{PCa}$, and the small number of positive samples for $H$. pylori. It would be interesting to look for $H$. pylori DNA in normal prostatic tissue of a control group.

\section{Conclusions}

This study provides, for the first time, evidence of the presence of $H$. pylori DNA in prostatic tissue of patients with $\mathrm{BPH}$ and PCa. The small number of PCa patients included in this study is the main limitation of the study in order to generate more positive samples as well as additional data related to significant statistical difference between BPH and PCa. This study should be an incentive for further multicenter studies to look for the association of $H$. pylori infection and $\mathrm{BPH}$ or $\mathrm{PCa}$, because if this is true then the management of these diseases could be reformed.

\section{Acknowledgements}

We would like to thank Mariam Al-Nabhani from the Department of Genetics for her technical assistance, and Hussein Al Senaidi (Urology Specialist Nurse) and Philomina (Urology OR nurse) for their clinical assistance. 


\section{References}

1 Forman D, Newell DG, Fullerton F, Yarnell JW, Stacey AR, Wald N, Sitas F: Association between infection with Helicobacter pylori and risk of gastric cancer: evidence from a prospective investigation. BMJ 1991;302: 1302-1305.

2 Nagashima R, Maeda K, Yuda F, Kudo K, Saitoh M, Takahashi T: Helicobacter pylori antigen in the glomeruli of patients with membranous nephropathy. Virchows Arch 1997;431:235-239.

3 Schistosomes, liver flukes and Helicobacter pylori. IARC Working Group on the Evaluation of Carcinogenic Risks to Humans. Lyon, 7-14 June 1994, pp1-241.

4 Correa P: Human gastric carcinogenesis: a multistep and multifactorial process-First American Cancer Society Award Lecture on Cancer Epidemiology and Prevention. Cancer Res 1992;52:6735-6740.

5 Al-Marhoon MS, Nunn S, Soames RW: The association between cag A+ H. pylori infection and distal gastric cancer: a proposed model. Dig Dis Sci 2004;49:1116-1122.

6 Pastuszka A, Slusarczyk K, Koszutski T, Kudela G, Kawalski H: Intravesical vaccination against Helicobacter pylori in patients with chronic cystitis may confer protection against MALT-type lymphoma of the bladder. Med Hypotheses 2007;69:1160-1161.

7 Al-Marhoon MS: Is there a role for Helicobacter pylori infection in urological diseases? Urol J 2008;5:139-143.

8 Elkahwaji JE, Zhong W, Hopkins WJ, Bushman W: Chronic bacterial infection and inflammation incite reactive hyperplasia in a mouse model of chronic prostatitis. Prostate 2007;67:14-21.

9 Hochreiter WW, Duncan JL, Schaeffer AJ: Evaluation of the bacterial flora of the prostate using a 16S rRNA gene based polymerase chain reaction. JURO 2000;163:127-130.
10 van den Bosch J, Kropman RF, Blok P, Wijermans PW: Disappearance of a mucosa-associated lymphoid tissue (MALT) lymphoma of the urinary bladder after treatment for $\mathrm{He}$ licobacter pylori. Eur J Haematol 2002;68: 187-188.

11 Isogai H, Isogai E, Kimura K, Fujii N, Yokota $\mathrm{K}$, Oguma K: Helicobacter pylori induces inflammation in mouse urinary bladder and pelvis. Microbiol Immunol 1994;38:331-336.

12 Ho SA, Hoyle JA, Lewis FA, Secker AD, Cross D, Mapstone NP, Dixon MF, Wyatt JI, Tompkins DS, Taylor GR: Direct polymerase chain reaction test for detection of Helicobacter pylori in humans and animals. J Clin Microbiol 1991;29:2543-2549.

13 Soylu A, Ozkara S, Alis H, Dolay K, Kalayci M, Yasar N, Kumbasar AB: Immunohistochemical testing for Helicobacter Pylori existence in neoplasms of the colon. BMC Gastroenterology 2008;8:35.

14 Shimoyama T, Kato C, Kodama M, Kobayashi I, Fukuda Y: Applicability of a monoclonal antibody-based stool antigen test to evaluate the results of Helicobacter pylori eradication therapy. Jpn J Infect Dis 2009;62: 225-227.

15 Balkwill F, Mantovani A: Inflammation and cancer: back to Virchow? Lancet 2001;357: 539-545.

16 Fox JG, Wang TC: Inflammation, atrophy, and gastric cancer. J Clin Invest 2007;117:60-69.

17 Coussens LM, Werb Z: Inflammation and cancer. Nature 2002;420:860-867.

18 Cohen RJ, Shannon BA, McNeal JE, Shannon T, Garrett KL: Propionibacterium acnes associated with inflammation in radical prostatectomy specimens: a possible link to cancer evolution? J Urol 2005;173:1969-1974.

19 de Martel C, Franceschi S: Infections and cancer: established associations and new hypotheses. Crit Rev Oncol Hematol 2009;70: 183-194.
20 Parkin DM: The global health burden of infection-associated cancers in the year 2002. Int J Cancer 2006;118:3030-3044.

21 Suarez F, Lortholary O, Hermine O, Lecuit M: Infection-associated lymphomas derived from marginal zone B cells: a model of antigen-driven lymphoproliferation. Blood 2006; 107:3034-3044.

22 Atherton JC, Blaser MJ: Coadaptation of Helicobacter pylori and humans: ancient history, modern implications. J Clin Invest 2009;119: 2475-2487.

23 Namiki K, Goodison S, Porvasnik S, Allan RW, Iczkowski KA, Urbanek C, Reyes L, Sakamoto N, Rosser CJ: Persistent exposure to Mycoplasma induces malignant transformation of human prostate cells. PLoS One 2009; 4:e6872.

24 Karatas OF, Turkay C, Bayrak O, Cimentepe E, Unal D: Helicobacter pylori seroprevalence in patients with chronic prostatitis: a pilot study. Scand J Urol Nephrol 2010;44:9194.

25 Urisman A, Molinaro RJ, Fischer N, Plummer SJ, Casey G, Klein EA, Malathi K, Magi-Galluzzi C, Tubbs RR, Ganem D, Silverman RH, DeRisi JL: Identification of a novel Gammaretrovirus in prostate tumors of patients homozygous for R462Q RNASEL variant. PLoS Pathog 2006;2:e25.

26 Barykova YA, Logunov DY, Shmarov MM, Vinarov AZ, Fiev DN, Vinarova NA, Rakovskaya IV, Baker PS, Shyshynova I, Stephenson AJ, Klein EA, Naroditsky BS, Gintsburg AL, Gudkov AV: Association of Mycoplasma hominis infection with prostate cancer. Oncotarget. 2011;2:289-297. 